\title{
Cosmology and Cartography
}

\author{
EDMOND POGNON*
}

Cosmology and cartography: immense subjects, the general compass of which gives me the perilous honour of contributing the first communication of this congress. It is; indeed, a subject which touches only indirectly on the problems of the Arctic regions which are our concern.

Cosmology is defined in almost the same terms by Larousse and Littre as "the science of the general laws which govern the physical world", and its influence on cartography is evident. The shape of the Earth and its relationship to the rest of the cosmos, or more exactly to the celestial bodies, are the very basis of cartography. To define them, or in other words to establish astronomy, is historically the first priority of cosmology, and at least since Newton it has been clear that this first step is of crucial importance to all other problems of cosmology.

All historical cognizable or even imaginable cosmologies may be placed in one of two categories: they are either scientific or irrational. Our own, in particular our astronomy, is scientific. We observe as exactly as possible the greatest possible number of phenomena, and we reason logically and mathematically from these data without reference to anything else.

It is hardly necessary to recall that in applying this method we are merely following, although with incomparably more effective means, the example first set in the sixth century B.C. by the Greek "physicists" of the Ionian school. It is equally well known that the concept inaugurated by these great minds culminated, for astronomy, in the Ptolemaic system which dates from the second century A.D. The stages of these eight centuries of progress are described in many books; however, since they concern the relationship of astronomy to cartography, there are some comments which should be made.

The Ptolemaic system has all the astronomical elements which are still used today in map-making: meridians and parallels of the celestial sphere projected onto the terrestrial sphere which is at its centre, polar circles and tropics deduced from the inclination of the terrestrial axis to the ecliptic, division of the circumference into $360^{\circ}$, the "compass rose" or mariner's compass. Of course, we no longer accept the Ptolemaic system - we no longer believe in the geocentric universe, and we have known since Copernicus that the Earth is a planet which orbits the Sun. Nevertheless, Copernicus' revolutionary work in astronomy, which had tremendous repercussions on cosmology as a whole, had no effect whatsoever on cartography. The astronomical observations which determine the latitude and longitude of a point on the surface of the earth (its coordinates) are in no way influenced; nor, in- deed, are the operations of the navigator who takes a bearing which is, in fact, the same thing. As Thomas S. Kuhn writes in his remarkable work The Copernican Revolution: "most treatises on aerial or maritime navigation open with a sentence such as 'For our present purpose, we shall assume that the Earth is a small stationary sphere at the centre of a larger celestial sphere which is in rotation.' ",

Although since the time of Ptolemy and even before, there has existed a theoretical idea of the Earth and its place in the Universe which was perfectly suited to cartographical work, the practical means of using it were hopelessly inadequate. Latitude was determined by using the old Egyptian gnomon, a vertical pylon, the length of whose shadow at noon gave the inclination of the sun. The lack of precision in this method is clear, and it could only be applied at a few points. As for longitude, it could only be measured by comparing the exact time at several locations - impossible with a sundial, or even with a clepsydra or sand-glass, which were much too inaccurate and not easily portable. It was only in the seventeenth century that a satisfactory solution was found via the invention of the chronometer.

So much for the technical methods of cartography in the Ancient World. To these impediments was added, of course, ignorance of the major part of the Earth's surface: Knowledge was limited to those regions which had been reached by travellers, navigators, and explorers. Thus it happened that astronomical theory engendered logical ideas, which later discoveries revealed to be false. For example, it was understood that the more perpendicular the sun's rays, the greater the heating effect. From this it was deduced that the zone between the tropics would be too fiery to be habitable. There was much debate as to whether the unknown lands of the southern temperate zone were inhabited. As for the regions circumscribed by the polar circles; where the rays of the sun fall very obliquely - and here is the indirect link mentioned at the beginning theory declared them uninhabitable because of the cold. But it was known, even if not universally believed, that at about the time of the death of Aristotle (222 B.C.), Pytheas, the explorer from Marseille, on his return from a daring voyage in the Atlantic, claimed to have reached a northern land which he called Thule, where there was abundant ice and where the sun did not set at the summer solstice.

Ptolemy, of course, was also a geographer, but he could describe only that portion of the earth's surface known in his time (which was called the oecumen), using only very approximate coordinates almost always determined by the distances in stadia between the points to be fixed from a reference meridian 
and parallel, in practice those which cross at Rhodes. These dubious coordinates, some $\mathbf{8 0 0 0}$ of them, were listed by him in tables which fill six volumes of his Geography. Ptolemy himself, or more probably a cartographer named Agathodemon who lived three centuries later, extracted from this data 26 regional maps and one map of the oecumen. They are drawn up according to the systems of projection described in the eighth book. To allow for the roundness of the earth, he constructed the regional maps (Figs. 1,2) on parallels which were arcs of concentric circles, crossed by rectilinear meridians. For the maps of the oecumen, in effect a flat map of the world (or at least of the part he knew), the rectilinear meridians were no longer suitable. This map claimed to represent the terrestrial sphere from latitude $26^{\circ} \mathrm{S}$ to $65^{\circ} \mathrm{N}$, and in longitude, from the Atlantic Ocean to China. The further north one goes from the latitude of Rhodes, the more untenable becomes the alteration in lengths produced by rectilinear meridians. Ptolemy provided for this by constructing curves of constant length on the concentric parallels on both sides of the Rhodes meridian, which was kept rectilinear. He called this projection "homeoteric", which means "very similar". The map thus obtained was named "the cloak-shaped map" because of its appearance (Fig. 3).

Since Ptolemy's world map included nothing north of $65^{\circ} \mathrm{N}$, it did not even extend to the polar circle. Indeed, the peripheral regions of the map could only offer imaginary configurations.

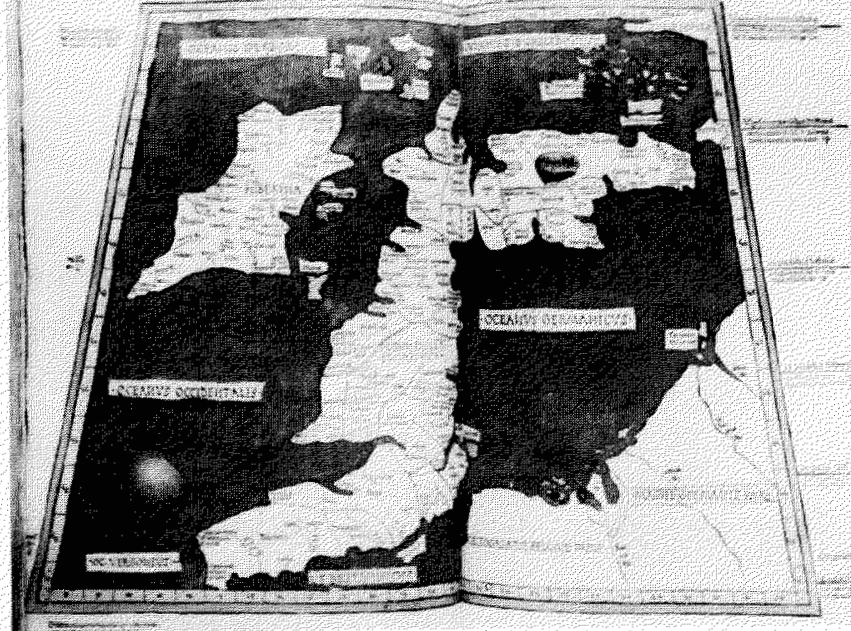

FIG I Ptolemy (1842), Geography. "Prima Europae Tabula". The most nor therly regional map of the work. Note the inscription "Oceanus iperboreus"

None of this diminishes the achievement of this great geographer and astronomer, who indisputably extracted the maximum from the theoretical and practical data at his disposal and who based his cartographical work rigorously on his cosmology.

This is perhaps the place to observe that the smaller the area covered by the map, the less the cartographer is limited by the shape he assumes for the Earth, and in general by his cosmol-

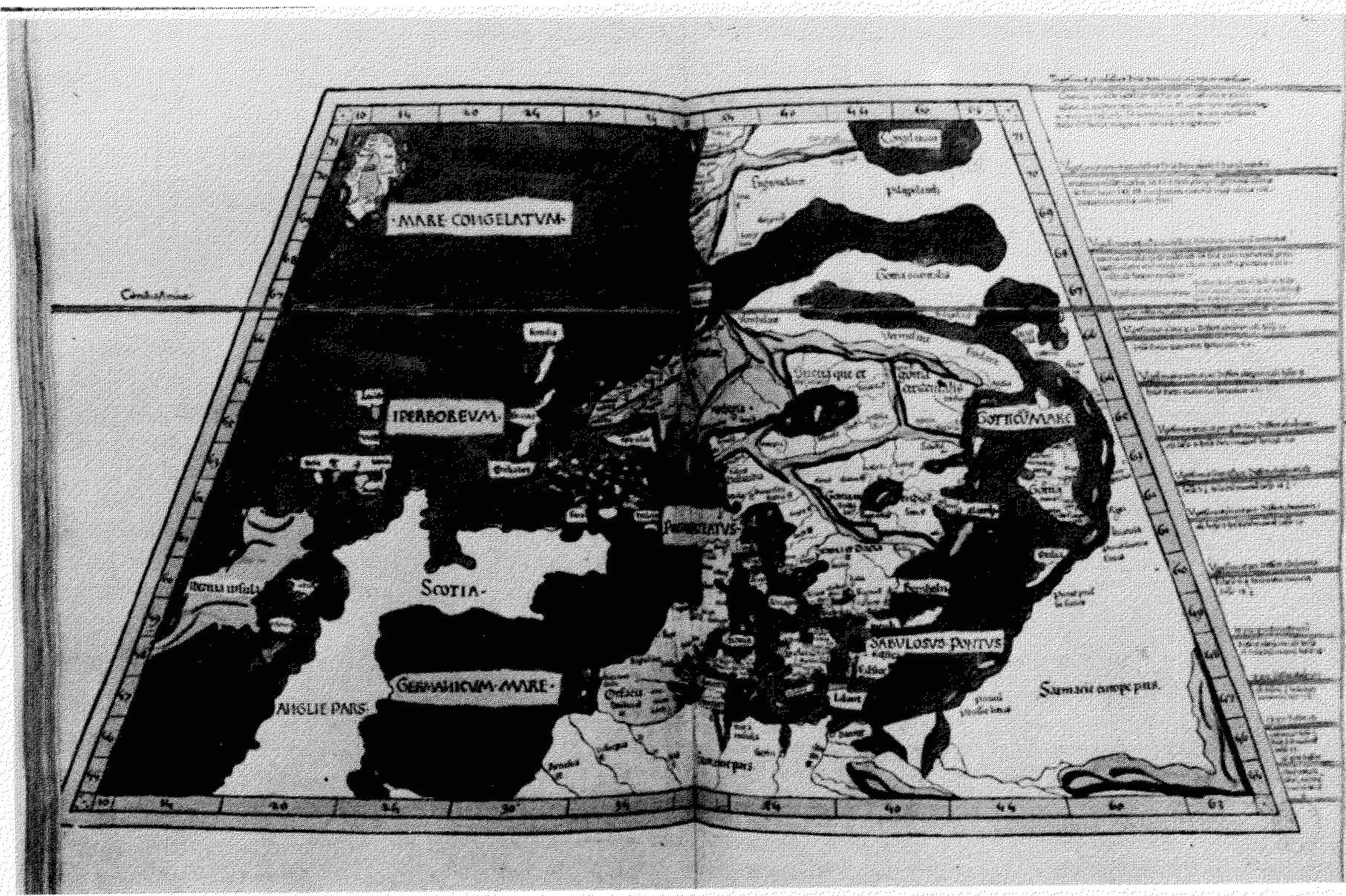

FIG. 2. Ptolemy (1842), Geography. Tabula nova', a map added to those drawn according to Ptolemy's coordinates and including recent discoveries. The polar circle is marked, and below is written "Mare congelatum". Further south one recognizes the Scandinavian peninsula and Denmark 


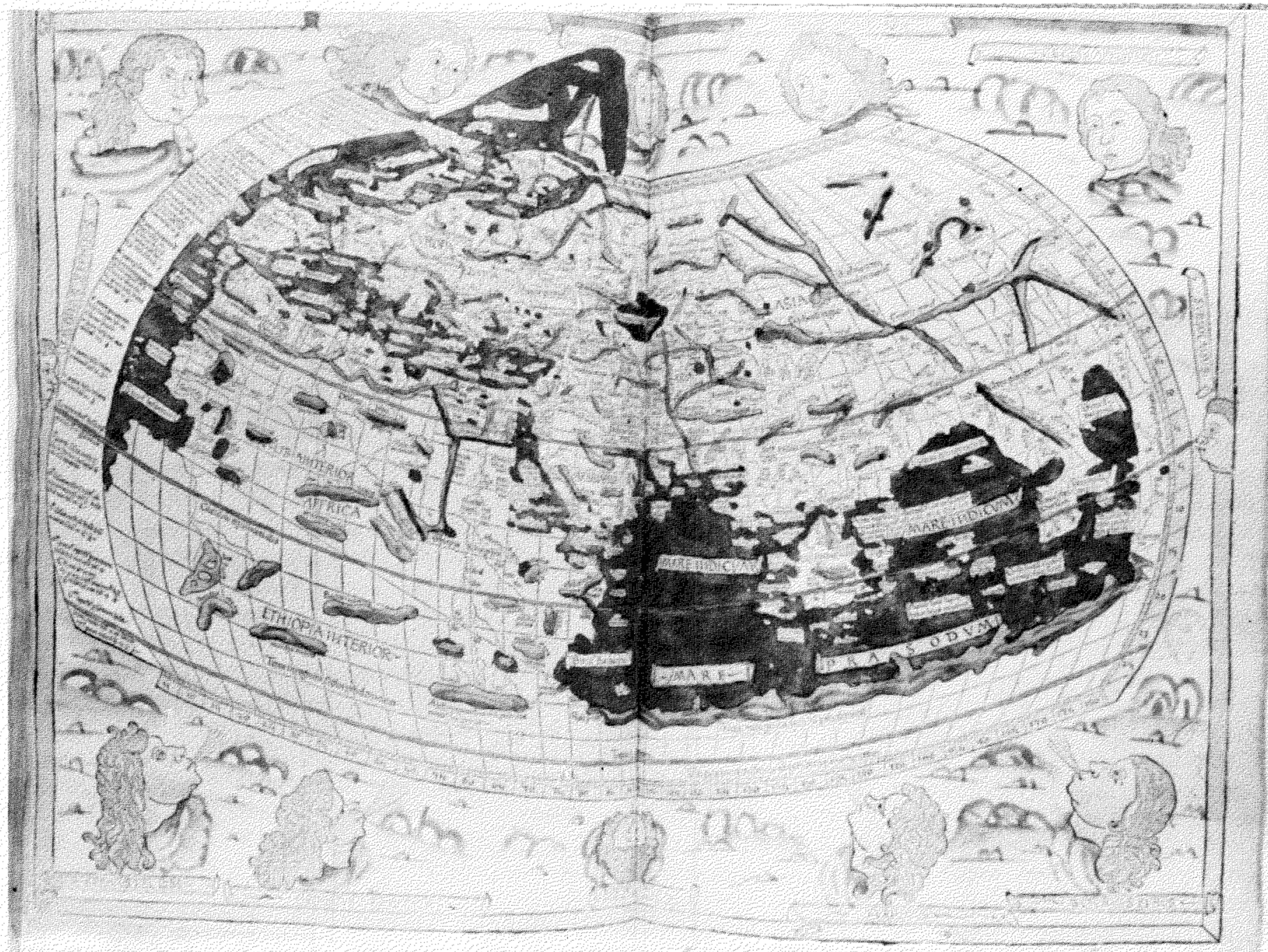

FIG. 3. Ptolemy (1842), Geography. The world map

ogy. Even today, for topographical maps, the processes of horizontal sighting - and now aerial photography - are more effective and more used than geodesy, from which we demand only an overall skeleton map. For plans, surveying is the proper technique. At the other extreme, flat maps of the Earth are the most directly influenced by the cosmology of the cartographer.

Abundant proof of these statements is provided by the world maps drawn in the early centuries of the Middle Ages. Nevertheless, they were preceded by a cartography which can be said to have been independent of any cosmology. Astronomy was still at the stage where Ptolemy had left it 150 years after his death, when Christianity triumphed in the Roman Empire with the famous Edict of Constantine of A.D. 313. The utilitarian and empirical spirit of the Romans, which dominated this period, sterilized the theoretical reflection which had been so fruitful among the Greeks and their immediate successors, the Alexandrians. As for cartography, it seemed to lose all relationship to astronomy. The new masters of the world did not need the general shape of the Earth, only convenient routes. It is probable that even the "Description of the World", ordered by Caesar and completed - by four engineers led by Agrippa -25 years later under Augustus, paid little heed to the example of Ptolemy.

The only sample of this cartography which we have is the map prepared by a certain Castorius, probably in the third century, and known only by a thirteenth-century copy, called after the collector who owned it, "Tabula Peutingeria" (Fig. 4). It is a strip $0.34 \mathrm{~m}$ high and $6.80 \mathrm{~m}$ long, on which itineraries that are in reality oriented in all directions are shown to be parallel. It is clearly a schematic diagram, designed to be drawn on an easily transportable scroll. Such a map - if the word can be applied to it - obviously has no connection with cosmology or astronomy.

The sudden eclipse of astronomical research after Ptolemy has an intrinsic cause. His world system gave a satisfactory account of astronomical phenomena insofar as they could be observed with the rudimentary means of the epoch. All seemed to be "finished": there was felt to be no need to complete or perfect astronomy, and no idea of how to do it. Ptolemy's 


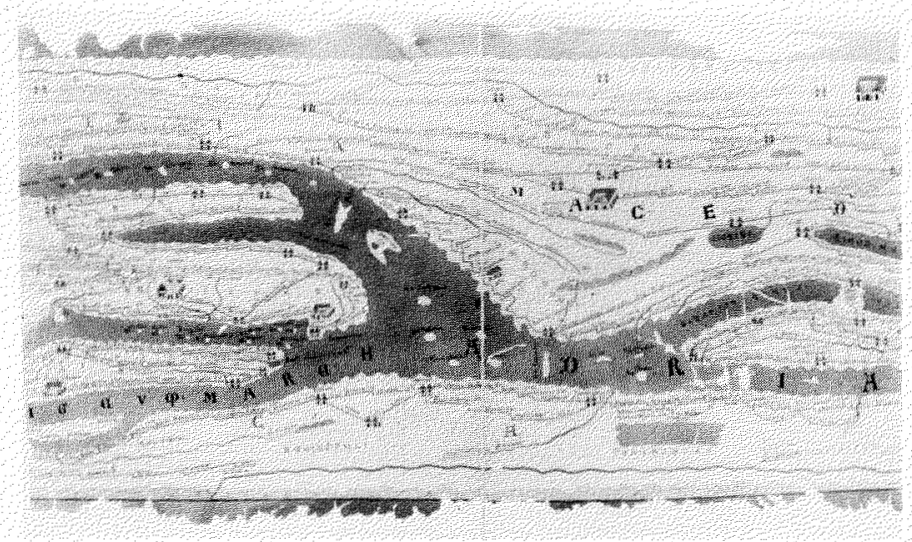

FIG. 4. The "Tabula Peutingeria (facsimile). Section showing southern Italy

authority was definitive. Never quite forgotten, restored intact in the thirteenth century (or at least in that epoch), reintroduced by Saint Thomas Aquinas (with Aristotelian philosophy, of which the world system was fundamentally the same), and widely recognized before the end of the Middle Ages, Ptolemy's astronomy, with allowances made for the refinements made necessary by progress in astronomical observation, dominated without question until Copernicus, and long resisted the strongest attacks.

However, at the beginning of the Middle Ages, Ptolemy was virtually dismissed by Christianity. Infinitely more structured than pagan mythologies, its unyielding adherents were directly persuaded that the entire truth of the world was contained in the Bible. Any assertion which seemed to contradict the letter of the sacred text could only be false. Above all, for the Church, which was only concerned with the salvation of souls in the next world, all objective knowledge of the visible world was irrelevant. The greatest of the Fathers of the Church, Saint Augustine, who had studied Greek science passionately before his conversion, wrote in his handbook for the use of Christians: "Thus, when we are asked our religious beliefs, it is not necessary to examine the nature of things, as did those whom the Greeks called physici...It is enough for the Christian to believe that the only cause of all created things, terrestrial or celestial, visible or invisible, lies in the goodness of the Creator, the only true God; and that nothing exists, except for Him, which does not draw its existence from Him."

From such a mental attitude, no cosmology could arise. However, the desire to denigrate pagan science produced a criticism of the world system which it had engendered, and consequently the need to replace it. This criticism and substitution owed almost nothing to observation of the visible world, drawing its arguments from sacred texts.

In the time of Constantine, Lactantius, preceptor of the emperor's son, drew attention to the fact that if the Earth were spherical, there would be sky above and below; as the sky is above, this cannot be so. Later in the fourth century, the bishop of Gabala proved that the sky is not spherical because God "stretcheth out the heavens as a curtain, and spreadeth them out as a tent to dwell in" (Isaiah XL:22). Genesis (I:7) tells us that there is water above the firmament and the Earth is flat. Two centuries later, a man from Alexandria named Cosmas (also known as Indicopleustès, meaning "seafarer in India"), who seems to have travelled a great deal on the Red Sea, the Indian Ocean, and the Persian Gulf, set up a complete cosmology inspired by the Scriptures. His universe had the form of the tabernacle which the Lord ordered Moses to construct in the desert: a flat base, vertical sides, and semi-cylindrical roof. The Earth, "the footstool of the Lord", became a plane twice as long as it was wide, and rested on the flat bottom of the universe (Fig. 5). The Sun did not pass beneath the Earth at night but hid behind an immense mountain which stood in the north. This northern mountain is the only equivalent in Cosmas's system to what we call the arctic regions.

The Church never officially adopted Cosmas's cosmology, nor did it censure those of its members - for all the intellectuals belonged to the Church - who, like Isodore of Seville in his encyclopedic work Etymologies or Origins, retained - insofar as the destruction or loss of countless texts allowed some fragments of ancient knowledge. There were always some who knew that the Earth was spherical and who situated it at the centre of the universe. At the end of the tenth century, a future pope named Gerbert d'Aurillac who held this opinion constructed celestial spheres.

As for cartography in the early centuries of the Middle Ages, it produced only world maps; no regional maps, and no topographical maps. Until the Renaissance these types of maps were rare. Nor is there any textual mention of maps, with the exception of plans of Rome and Constantinople engraved on a silver table (and thus no doubt converted sooner or later into denarii) which, according to Eginhard, was owned by Charlemagne. It must be said in passing that it is surprising that people who spent their lives arguing over and dividing territory should have dispensed so easily with a visual aid which seems so necessary to us. There is a temptation to imagine that they had an intuitive perception of surrounding or even distant space which escapes us today.

Among the world maps of this period there are some which are of special interest here: those which, reflecting traces of

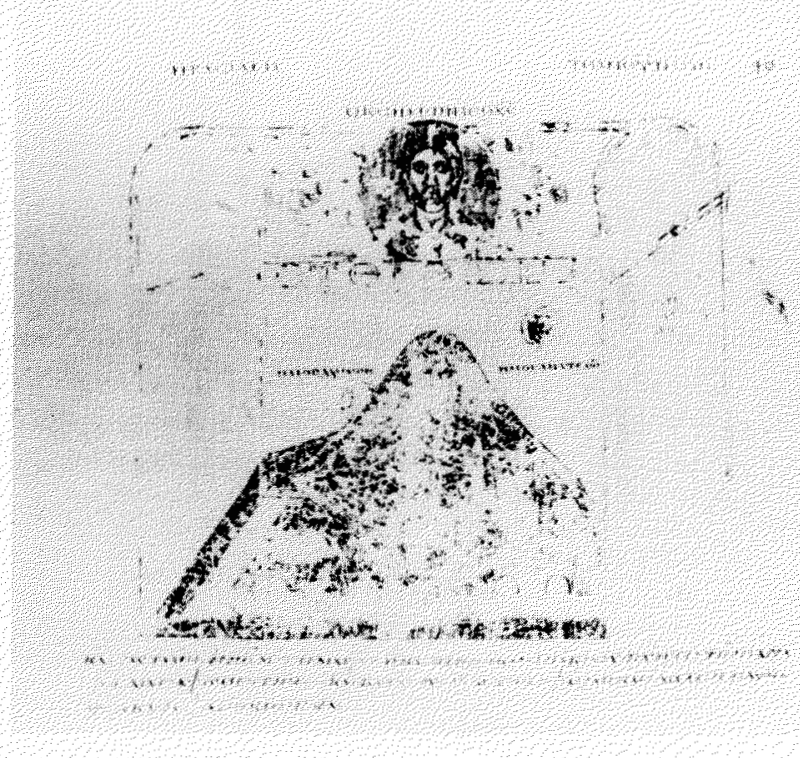

Fio. 5 . The universe according to Cosmas (facsimile) 
ancient science gleaned by their authors from encyclopedists such as Isidore of Seville or the Venerable Bede, whose work dates from the first half of the eighth century, make mention of the "fiery" tropical zone and of the cold which renders uninhabitable the two glacial zones. The most outstanding maps were described by the Vicomte de Santarem in his Essai sur l'histoire de la cosmographie et de la cartographie pendant le moyen age, printed in Paris in 1850. Two of these suffice to show that the notion of uninhabitable zones was accepted, but in no way understood, by the draughtsmen of these maps.

First, there is a world map which may be seen in a very important ninth-century manuscript kept at the Bibliothèque Nationale de Paris (Latin 4860, $f^{\circ} 100$ ), following a treatise entitled Liber rotarum sancti Isidori (Fig. 6). Here the Earth is clearly conceived as a flat disc. The double circle which surrounds it is called the "River Ocean", which, since the time of Homer, was thought to surround the Earth. In this way, all the later findings of Greek science were buried. Only the idea of uninhabitable zones survived, and as the draughtsman understood nothing of those, he distributed them as best he could, inside the disc among five smaller circles. There is a sixth cir-

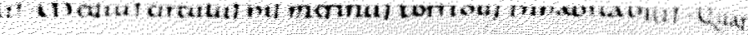

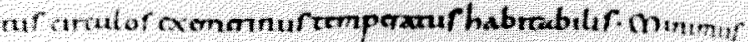

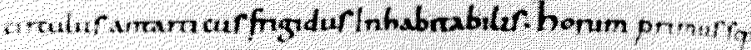

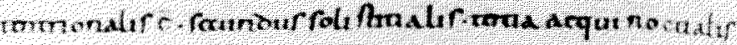

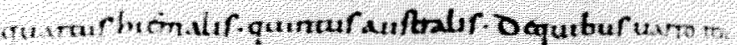

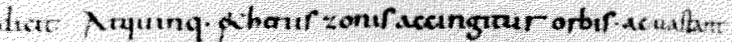

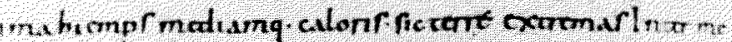

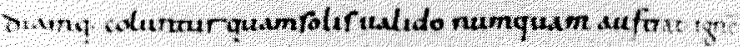

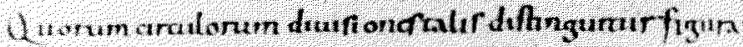

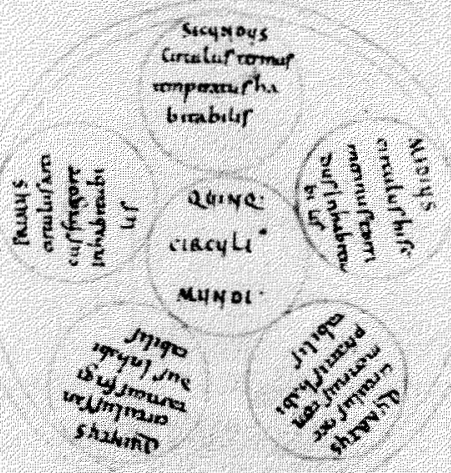

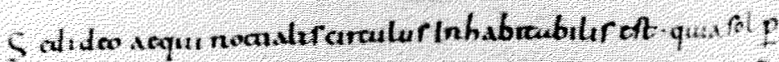

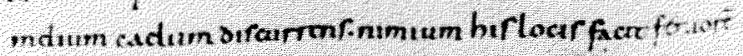

I wama frugeribunurancurpropar cailam mot the

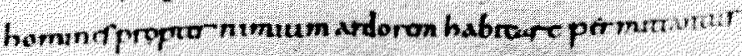

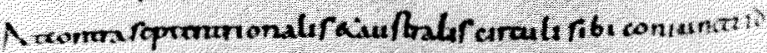

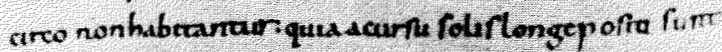

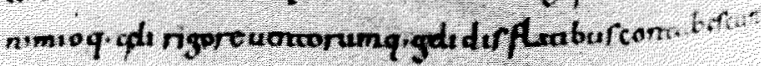

FIG. 6. The world map of Libe- rotarum (Bibliotheque nationale de Paris, MS lat. 4860 , f. $100 \mathrm{v}$.).

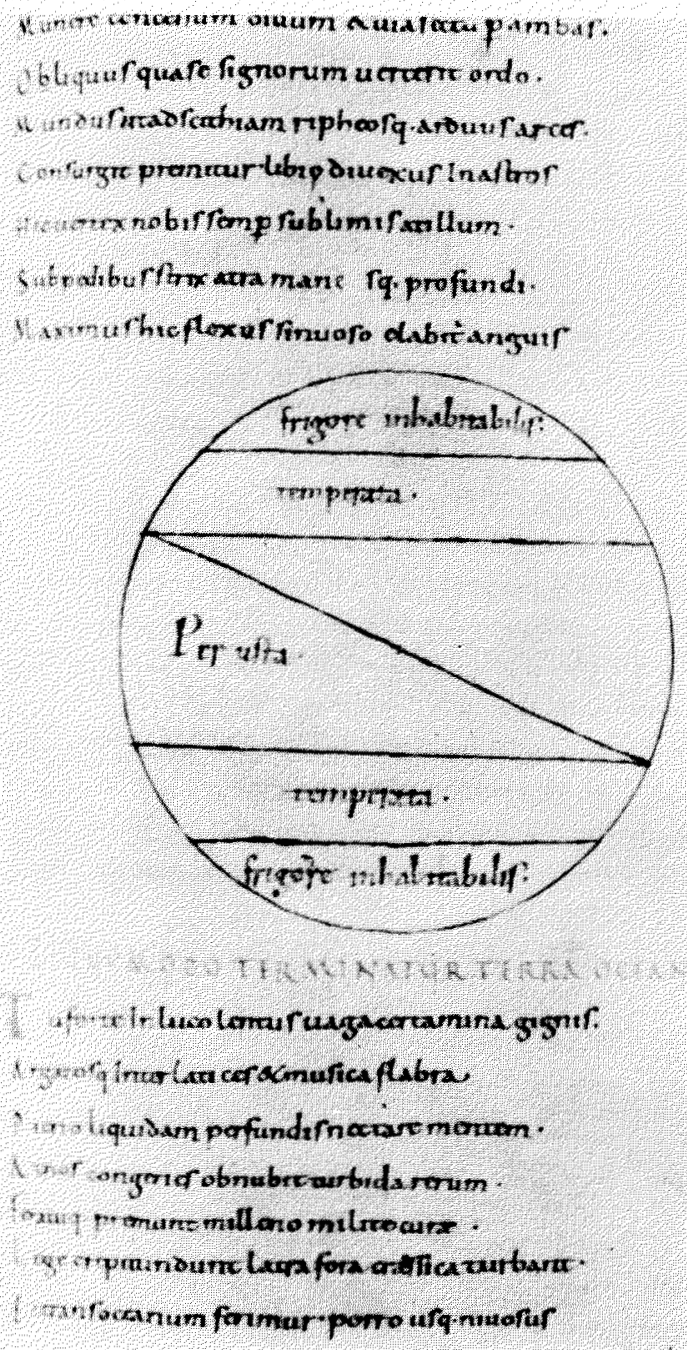

FIG. 7. The world map of De partibus Terrae (Bibliothèque nationale de Paris f. 107).

cle at the centre which frames the title "Quinque circuli mundi". The commentary may be translated as follows: "In their description of the world, the philosophers speak of five circles, which the Greeks called parallels, and which they call zones, into which the circle of the Earth is divided." And the author cites a hemistich of the Georgics: "Quinque tenet coelum zonas". He continues: "Let us think of this as our right hand; the thumb is the Arctic circle, uninhabitable because of the cold; the index, the second circle, temperate and habitable; the middle finger, the torrid circle, uninhabitable; the ring-finger, the fourth circle, temperate and habitable; the little finger, the Antarctic circle, cold, uninhabitable." There is not the least explanation of these temperature variations, and for good reason: the author had no inkling of the spherical nature of the Earth and appears to have had no notion of the celestial sphere.

In the same manuscript, following the chapter "De partibus Terrae", another world map (Fig. 7) is shown, a little less incompatible with reality in that the zones are delimited by parallel lines perpendicular to a north-south axis. The two extreme zones, our Arctic and Antarctic glacial zones, bear the 


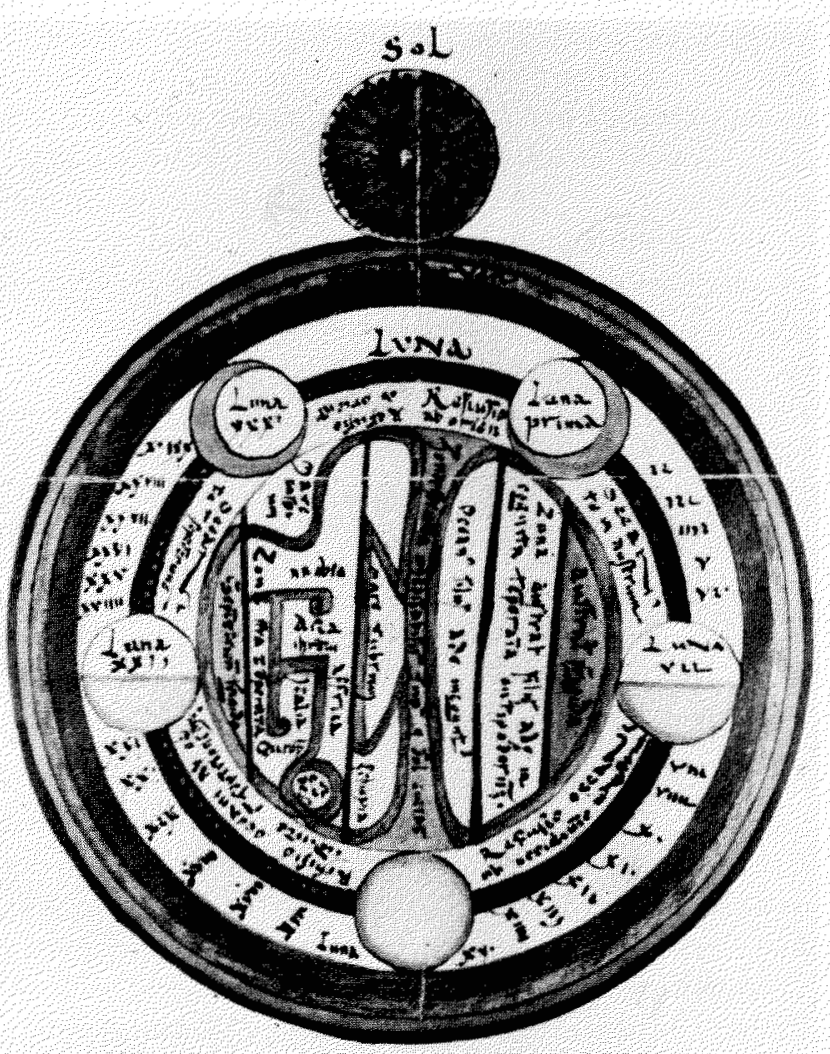

FIG. 8. Document not described in text. World map illustrating a manuscript of the encyclopedic work of Lambertus Floridus (about 1120, St. Omer), conserved at the Library of Ghent. Oriented with North to the left. The disc is surrounded by the phases of the Moon. Above, East, is the Sun. The zones are clearly distinquished. Those in red are "uninhabitable". (Facsimile published by the Vicomte de Santarem, about 1855).

caption "Frigore inhabitabilis". Two other parallels, which correspond approximately to the Tropics, delimit the torrid zone, characterized by the word perusta, which may be translated as "consumed", or "completely burned". An oblique line across this zone indicates that the draughtsman had some idea of the zodiacal band (Fig. 8).

These world maps and others which crop up throughout the Middle Ages touch on the theme of this congress in their mention of the glacial zones. They are of interest to my discipline in that they bear witness to a memory of the rational cosmology of the Ancients, even if this memory is vague and illunderstood. However, most world maps of the early centuries of the Middle Ages betray a total loss of the astronomical notions synthesized by Ptolemy, and a very sketchy and purely schematic knowledge of the three parts of the world then known.

The most characteristic type of these representations of the Earth is that known to historians as "T-O world maps". The Earth is depicted as a disc surrounded by the "River Ocean", a legacy of the Homeric tradition. It is divided into three by a horizontal line supposed to correspond to the River Tanais (the Don), prolonged by the Nile and separating Asia, the upper part of the disc, from Europe and Africa. Between these two latter parts of the world, a vertical line represents the Mediterranean. At the centre of the disc, where the two lines cross, Jerusalem is often situated.
These T-O world maps - $a$ " $T$ "' in an " $O$ " - ritually illustrate in the manuscripts of the period certain passages of Isidore of Seville (Fig. 9), the Venerable Bede, Sallust's Bellum Jugurthinum and Luean's Pharsalia. A passage of Glaber's Histoires, written in the 1040s and which has not, to my knowledge, been quoted by historians of medieval cartography, seems to explain very clearly the mystic and symbolic significance of these maps. Observing that Christianity had conquered the regions of the north and the west and not the eastern or southern countries of the world, Glaber added: "This was indeed presaged, in all truth, by the position of the Cross of Our Lord, when he hung on Calvary: behind the back of the Crucified lay the East and its bloodthirsty people, before His eyes lay the West, ready to be flooded by the light of faith; similarly His all-powerful right hand, open for acts of mercy, stretched towards the North which knew the bliss of belief in the holy word; but his left hand was reserved for the South, teeming with barbarian peoples."

This text seems to be the perfect commentary on these world maps which, while omitting the detail of real configurations,

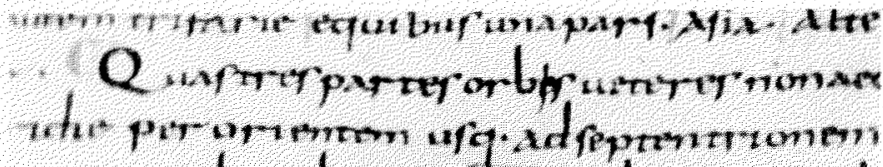

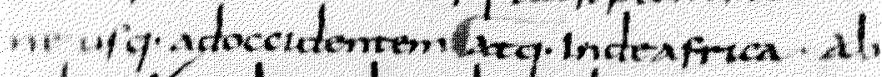

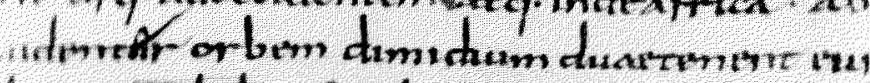

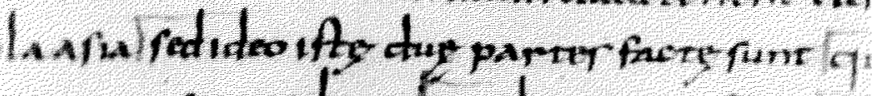

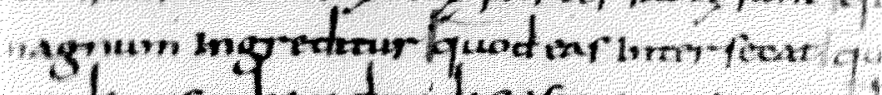

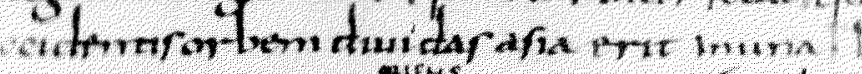

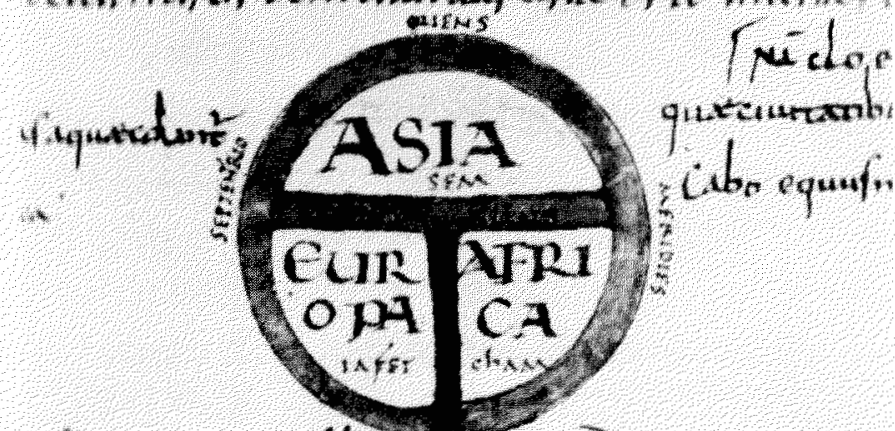

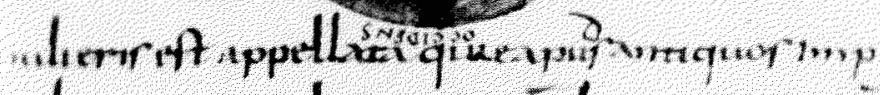
"bur parter dut po fitavabortente:

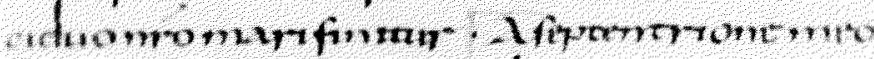

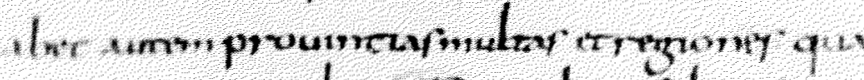

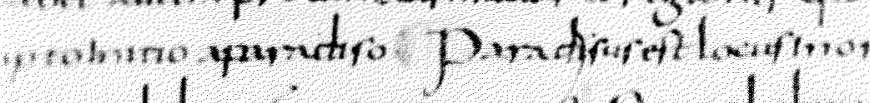

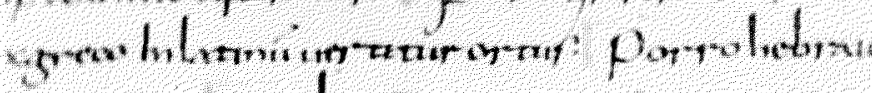

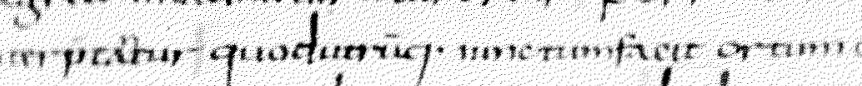

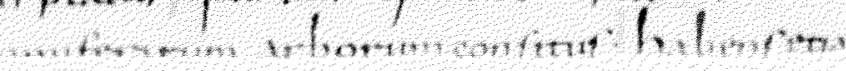

FIG. 9. A T-O world map illustrating the geographical part of the Etymologiae of Isidore of Seville, tenth century. (Bibliotheque nationale de Paris, MS lat. 7583). The names of the sons of Noah are associated with those of the three parts of the world. Asia-Shem, Europa-Japheth, Africa-Ham. 


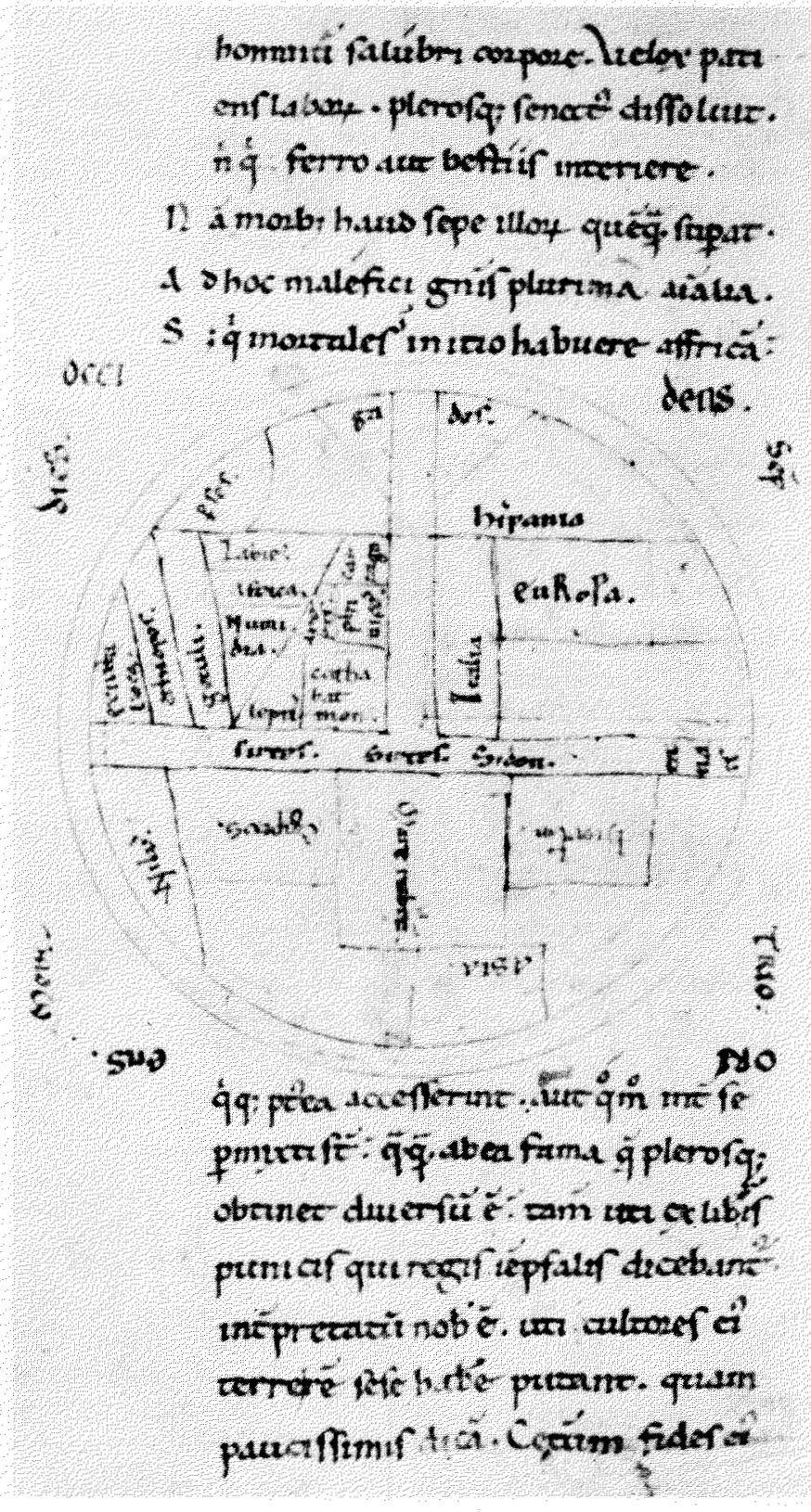

FiG. 10. World map 'from Sallust's Bellum Jugurthinum twelfth century. (Bibliotheque nationale de Paris, MS lat: 6253, f. 52v.). The T-O structure allows a relatively rich nomenclature. The map is oriented with the North to the right rather than the left, which was usual.

divide the earth in the sarne way. Such representations are almost exclusively inspired by an irrational cosmology, which owes practically nothing to concrete knowledge. Naturally, during the Middle Ages - which lasted 1000 years and were in no way the long peried of ignorance and "obscurantism" alleged by detractors - cartography made noticeable progress. Eleventh-century world maps are found on which the still very inexact configurations of the terrestrial surface are much more detailed; and which, little by little, escape from the T-O scheme (Fig. 10).

Before concluding, we must note at least briefly the medieval nautical charts known as portulans. They are actually outside the scope of this congress, because they are centered on the Mediterranean and not one approaches the glacial zones. But they are not without links with cosmology, as their creation depended on the bearings to be maintained in navigating from one point to another. These bearings were maintained at sea thanks to the compass introduced to the West in the twelfth century - a compass that indicates a North which differs from astronomical North. The draughtsmen of portulans, the most ancient of which is the "Pisan Chart" in the Bibliothèque Nationale de Paris, which appears to date from around 1300 , seem to have considered only magnetic North, and drew their charts not on lines of latitude and longitude, but on several compass roses (mariner's compasses) placed in the sea at given positions whence radiated straight lines indicating the various azimuths. These are known as "rhumbs". To find his heading, the navigator drew a straight line between his point of departure and his destination and observed to which rhumb-line it was parallel.

Paradoxically, this rhumb-line mapping led to a representation of the Mediterranean noticeably more accurate than would then have been obtained using meridians and parallels, as the degree of longitude inherited from Ptolemy was greatly overestimated.. The first "scientific" maps, which appeared in the sixteenth century and which were believed then to be closer to reality; were, for this reason, much less accurate than the old portulans. They attributed a greatly exaggerated width to the Mediterranean. 